\title{
LEAD TIME REDUCTION USING VSM AND MIS FOR DEVELOPING TAPER ROLLER BEARING SECTOR
}

\begin{tabular}{|c|c|}
\hline Vaidant Dixit $^{{ }^{*}}$ & A. M Gohil2 \\
Mechanical Dept. $^{\text {FOE, MEFGI }}$ & Mechanical Dept. \\
Rajkot, India & ITNU, Nirma University \\
vaidant.dixit@ marwadieducation.edu.i & Ahmedabad, India \\
& Ashish.gohil@ @irmauni.ac.in \\
\hline
\end{tabular}

\begin{abstract}
To remain competitive in the market today companies are striving to reduce the lead time to manufacture their products. This paper deals with problems faced by bearing manufacturing company SKF (Svenska KullagerFabriken) like unnecessary transportation, inventory stack up and waiting. In order to reduce this waste, lean manufacturing tools such as Value Stream Mapping (VSM), takt time production planning and pull system is implemented. As a result of these tools, lead time has been reduced, and thus eliminating non value added activities. During the first phase of the project, problems are identified which affects the total lead time of TRB (Taper Roller Bearing rings). Relevant data is collected using Time and motion study. Then data analysis is carried out using Evaluation priority matrix and Pareto analysis and thus significant factors are listed out. The main tool used during this phase is Value Stream Mapping (VSM) which helps in mapping the current state and how it can be modified and projects as a future state. In the second phase, work has been carried out on designing and developing an online Management Information System (MIS) which is solely for Taper Roller Bearing rings sector so that their transactional activities can be carried out using this software.
\end{abstract}

Keywords - Value Stream Mapping; Management Information System; Material Requisition.

\section{INTRODUCTION}

For a bearing manufacturers, where competition is very high along with quality of products lead time is an important factor to satisfy the customer. SKF Ahmedabad is currently involved in a business relationship with SKF Pune, i.e. providing heat treatment facilities to Pune-TRB rings. But, it's a complete grey business area. Now the problem is that, complete movement and the status of all different types of bearings which is an internal product and belongs to internal stake holders are under scrutiny and has been captured using a database software called Mapics. But as far as the Pune- TRB activities are concerned, it is a bottleneck area which includes lack of planning schedule, and its complete process flow is not captured. So most of the time, new business area hampers the production of internal material and thus production plans seems to be not working. In the existing setup the problem is that it consumes more time for setup and also more workers are required to make arrangements for heat treatment of TRB and thus results into an increase lead time. In this paper emphasize is on employing lean tool i.e. Value stream mapping along with MIS development to achieve the
Objective i.e. to reduce lead time and to stream line the process flow of TRB rings.

A way of doing VSM is presented through the following: Data of Cycle time, waste time, in-process queue time, Data gathering for percent rejects and work-in-process, Gemba, Establishing VSM, and Monitoring [2]. To evaluate potential gains from implementing VSM, a simulation software Arena can be used which gives detail idea about the time involved in value and non-value adding activities. [3]. A number of real life maps drawn across the different industries like electronic, mechanical, food processing etc. and it clearly illustrates the change in requirement and working strategy according to working environment of various companies [5]. One effective way is to compare the cycle time of each process with the takt time which is available and thus infers which process needs to be work upon and how its process capability can be improved [6]. A real-time information-sharing platform and decision making system is designed that allows information transfer among various departments and results in timely production and decision support for the Make to order type manufacturing [7]. In a manufacturing industry and other core industries, implementing an MIS not only helps as online database system but also it helps to distinguish the works at firm site and project site [8].

\section{METHODOLOGY}

\section{A. Problem Identification}

For problem identification, firstly the whole material route and other activities are thoroughly studied as shown in Fig.1. And problems are listed in Table I.

Ravi Techno forge, Rajkot is vendor of soft turned TRB rings. Second activity is to receive that shipment from supplier by the SKF Store/LSB India department. As per the production schedule, and keeping in mind the proposed delivery date, Supply chain department take initiative to generate a Manufacturing Order (M.O.) which is accessed by heat treatment department and depending upon the M.O. their planning of production start taking place. Fourth activity is material requisition procedure, where a requisition for the related material needs to be raised by the heat treatment plant so that LSB India department will provide the materials as per their requirement from their dock area. Now heat treatment 


\section{Asia Pacific Journals}

procedure starts where the whole lot are divided into no. of batches suitably and they all goes past the roller hearth furnace. After heat treatment activity, rings metallurgical properties are tested in a metallurgical lab and thus based on test reports, information is conveyed to SKF Pune. If the test reports are up to the mark, whole lot after H.T. returned to stores and then accounts department raised related bill and invoice to the account section for bill generation. Then using external shipment lot is delivering to SKF Pune campus. The total lead time proposed by SKF Ahmedabad is 12 to 14 days.

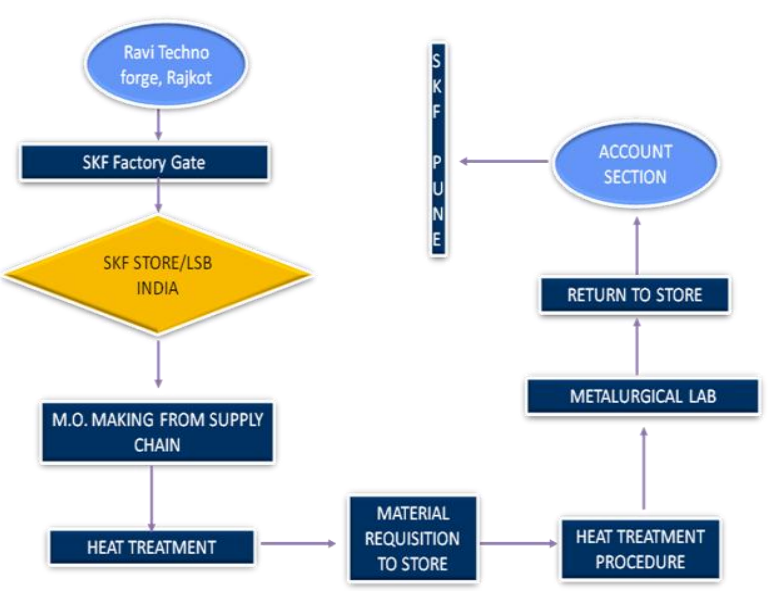

Fig. 1. Pune TRB Process Flow Chart

TABLE I Problems in current Pune TRB Set up.

\begin{tabular}{|l|l|}
\hline Sr. No & Problems Identified \\
\hline 1 & $\begin{array}{l}\text { Lack of planning and communication } \\
\text { (supplier and customer side) }\end{array}$ \\
\hline 2 & $\begin{array}{l}\text { Status and movement of material } \\
\text { uncaptured }\end{array}$ \\
\hline 3 & Excessive throughput time \\
\hline 4 & $\begin{array}{l}\text { Furnace settings changeover } \\
\text { and operators) }\end{array}$ \\
\hline 5 & \begin{tabular}{l} 
Manual handling of rings \\
\hline 7
\end{tabular} \\
\hline 9 & Basic facilities deficit \\
\hline
\end{tabular}

\section{B. Data Collection}

For data collection, time and motion analysis technique is employed where focus is on how the material of Pune- TRB flows after it is received at company campus from supplier. Table II is all about the transaction details between the heat treatment plant and the semi-finished product stores (LSB INDIA). Here, time study has been done over the movement of rings in the factory campus itself. Data regarding part no, quantity, issue date to HT (Heat Treatment), received date and the date of dispatch along with quantity has been summarised and ultimately this gives an idea about the time taken by materials to move from factory gate to the same. Table clearly depicts variation from 7 to 84 days in lead time.

TABLE II Throughput Time for Pune TRB Material

\begin{tabular}{|c|c|c|c|c|}
\hline $\begin{array}{c}\text { Type } \\
\text { (Quantity) }\end{array}$ & $\begin{array}{c}\text { Date of } \\
\text { issuing to } \\
\text { H.T. }\end{array}$ & $\begin{array}{c}\text { Received } \\
\text { Date }\end{array}$ & $\begin{array}{l}\text { Dispatch } \\
\text { Date }\end{array}$ & $\begin{array}{l}\text { Throughput } \\
\text { time (in days) }\end{array}$ \\
\hline $\begin{array}{c}\text { OM672 } \\
(112)\end{array}$ & 15-Oct-12 & $\begin{array}{l}\text { 14-Dec- } \\
12\end{array}$ & 18-Dec-12 & 64 \\
\hline $\begin{array}{c}\text { IM33019 } \\
(2007)\end{array}$ & $\begin{array}{c}\text { 15-Dec- } \\
12\end{array}$ & 8-Jan-13 & 8-Jan-13 & 23 \\
\hline $\begin{array}{c}\text { OM33019 } \\
(2028)\end{array}$ & $\begin{array}{c}\text { 15-Dec- } \\
12\end{array}$ & 8-Jan-13 & 8-Jan-13 & 23 \\
\hline $\begin{array}{c}\text { IM30214 } \\
(1000)\end{array}$ & $\begin{array}{c}\text { 20-Nov- } \\
13\end{array}$ & $\begin{array}{c}25-\text { Nov- } \\
13\end{array}$ & 08-Dec-13 & 19 \\
\hline $\begin{array}{c}\text { IM32214 } \\
(216)\end{array}$ & 28-Jan-13 & $\begin{array}{c}19-A p r- \\
13\end{array}$ & 19-Apr-13 & 84 \\
\hline
\end{tabular}

\section{Data Analysis}

After the problem identification and data collection it has clear that there is a huge gap between the proposed and current lead time scenario. So, for further analysis Evaluation and priority matrix technique is employed to find out the severity quotient of each problem that has identified. For this task, four criterions i.e. safety, cost, quality, ease of implementation and productivity are decided and accordingly each factor is rated on a scale of 5 to decide the order of severity of problems. Result of Evaluation-Priority matrix is shown in Table III.

TABLE III Evaluation-Priority Matrix

\begin{tabular}{|c|l|c|c|c|c|c|}
\hline $\begin{array}{c}\text { Sr } \\
. n \\
\text { o }\end{array}$ & Criterion & Cost & Quality & $\begin{array}{l}\text { Ease of } \\
\text { impleme } \\
\text { ntation }\end{array}$ & Productivity & $\begin{array}{c}\mathrm{T} \\
\mathrm{O} \\
\mathrm{T} \\
\mathrm{A} \\
\mathrm{L}\end{array}$ \\
\hline 5 & $\begin{array}{l}\text { Excessive } \\
\text { throughput } \\
\text { time }\end{array}$ & 5 & 5 & 4 & 5 & 19 \\
\hline 2 & $\begin{array}{l}\text { Status and } \\
\text { movement } \\
\text { of material } \\
\text { uncaptured }\end{array}$ & 3 & 5 & 5 & 5 & 18 \\
\hline 1 & $\begin{array}{l}\text { Lack of } \\
\text { planning } \\
\text { and } \\
\text { communica } \\
\text { tion }\end{array}$ & 5 & 3 & 4 & 5 & 17 \\
\hline
\end{tabular}


Asia Pacific Journals

\begin{tabular}{|c|l|c|c|c|c|c|}
\hline 9 & $\begin{array}{l}\text { Basic } \\
\text { facilities } \\
\text { deficit }\end{array}$ & 5 & 4 & 4 & 3 & 16 \\
\hline 3 & $\begin{array}{l}\text { Predefined } \\
\text { cycle time }\end{array}$ & 2 & 5 & 3 & 5 & 15 \\
\hline 2 & $\begin{array}{l}\text { Manual } \\
\text { Handling of } \\
\text { rings }\end{array}$ & 2 & 3 & 5 & 4 & 14 \\
\hline
\end{tabular}

Another method used for analysis is Pareto Analysis which helps in scrutinizing the most important changes to make. First of all it required to group together the different types of problem occurred, and then count the number of cases of each type of problem. By prioritizing the most common type of problem, focus should be there for resolving it. Result of Pareto analysis is shown in Fig. 2.

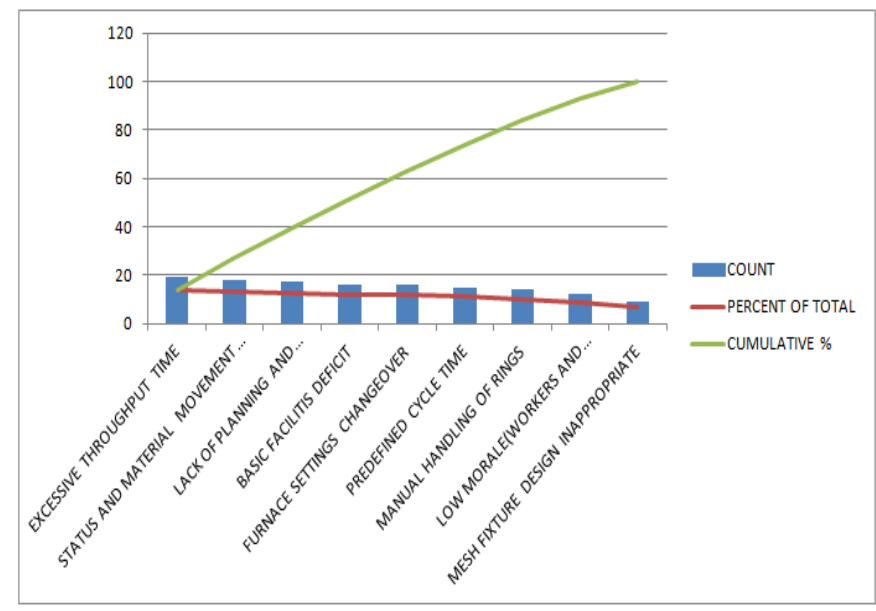

Fig. 2. Pareto Analysis

\section{VALUE STREAM MAPPING}

Takt time is the total time elapsed between two consecutive Items which is to be produced. It can be calculated by dividing the net working time available for the production to the customer demands per day or say per shift. Since TRB are not frequently ordered rings, so demand is considered as the average no. of rings produced in a calendar year 2013. So from the data which has been collected from Jan 2013 till December 13, it is calculated that demand per day working is approximately 1172 rings. Regularly two shifts have been carried on per day with net working time available is 16 hours (960 minutes) excluding the time spent for non-productive activities. So, takt time which is available is 0.82 minutes per ring.

Current and future state of map has been drawn as shown in Fig. 3 and Fig.4 respectively.

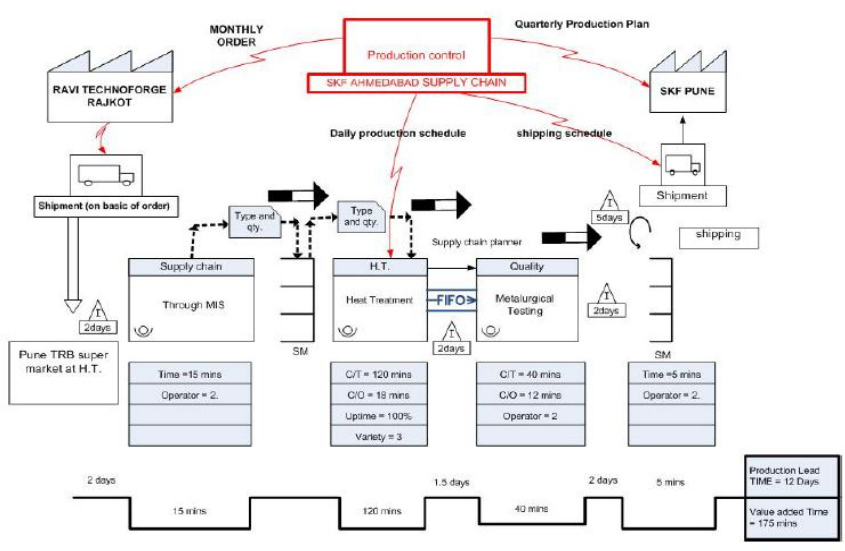

Fig. 3. Current State Map

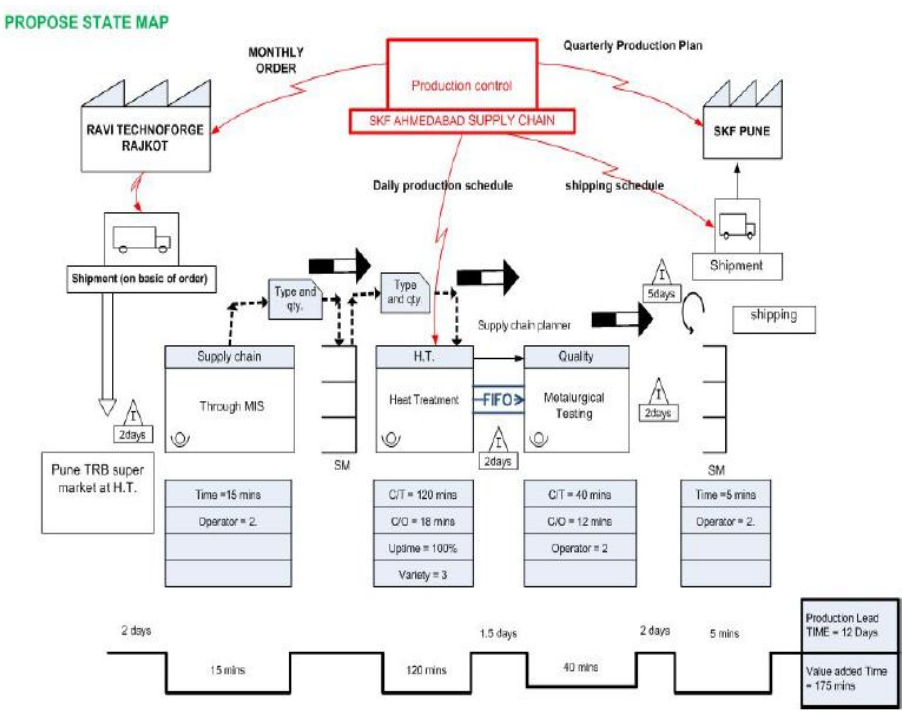

Fig. 4. Future State Map

\section{DEVELOPMENT OF MIS}

Since Pune-TRB is not an internal product, there is no legal transactions has been made regarding the arrival, processing or say dispatching of product. There is no provision of entering the details of this product in Mapics and also no separate system is devoted to this business. A basic solution which can address this problem is to design and develop an

Separate Management information system which can be accessed by only those internal stake holders along with customer involved. The benefits like status and current location of the TRB rings can be tracked as well as the whole activities related to this will carry out timely. So a MIS is developed using M.S. Access 2007 as a platform. 


\section{Asia Pacific Journals}

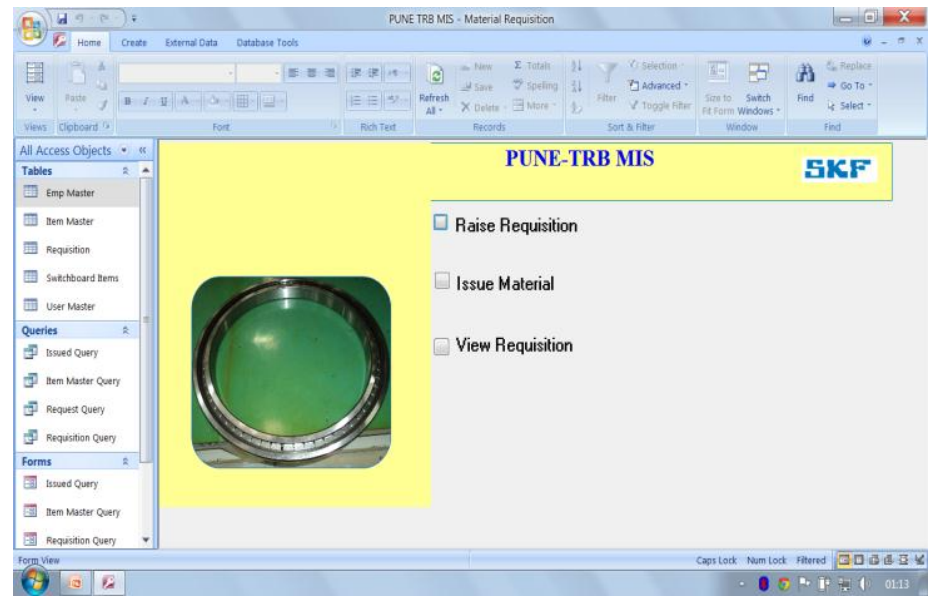

Fig. 5. Main Switchboard of MIS

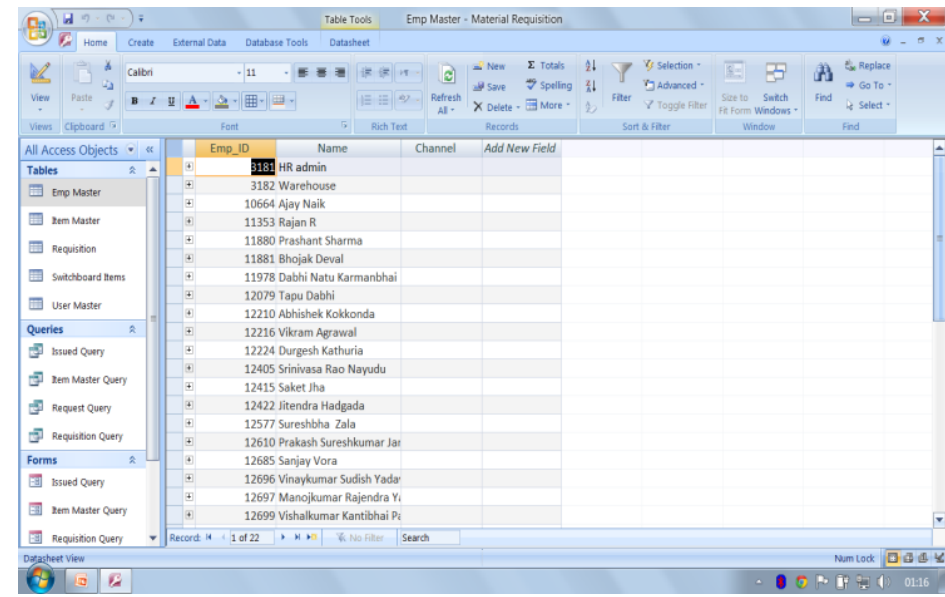

Fig. 7. Employee Master Table
Main switchboard is the front end display which appears first on computer screen as the access to start MIS. It is one of the forms which show all the options necessary to operate the MIS as shown in Fig.5. This switchboard has been customized such that the user has to select the relevant option by clicking the check box and all related features and data would be extracted from the database which is created in the back tier.

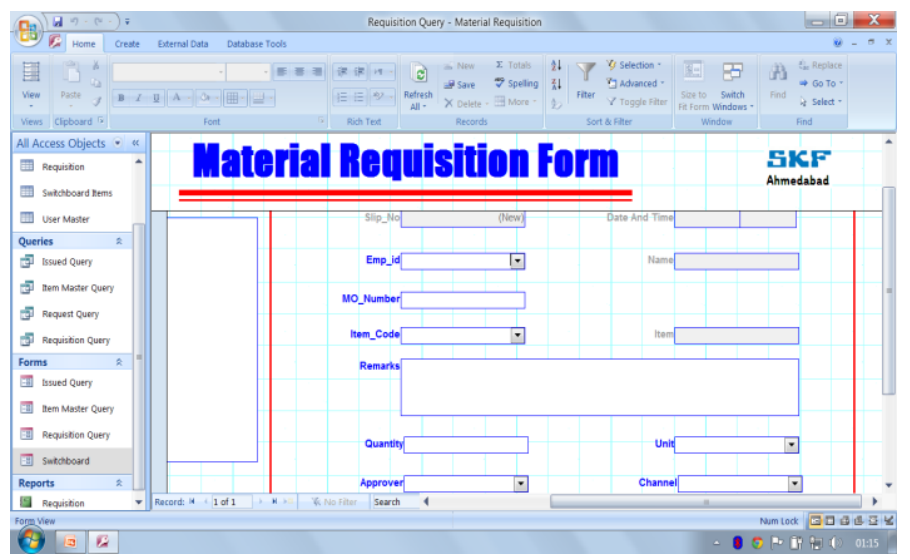

Fig. 6. Material Requisition Form

Fig.6 shows Material requisition form which is generated once the raise requisition option is click and thus relative stake holder filled the form as per its requirement and save the new order.

Fig.7 shows the employee master table which consist the details like the Employee identification, Name and Respective channel so that while filling the material requisition forms or while accessing other options, name and employee identification is generated automatically.
As shown in Fig.8, Item master table consist of the bearing designations along with designation of other accessories such as angle ring with the part detailing for all the Pune TRB rings which need to be processed in SKF Ahmedabad factory. By viewing this table item code and other details can be derived while filling the requisition form.

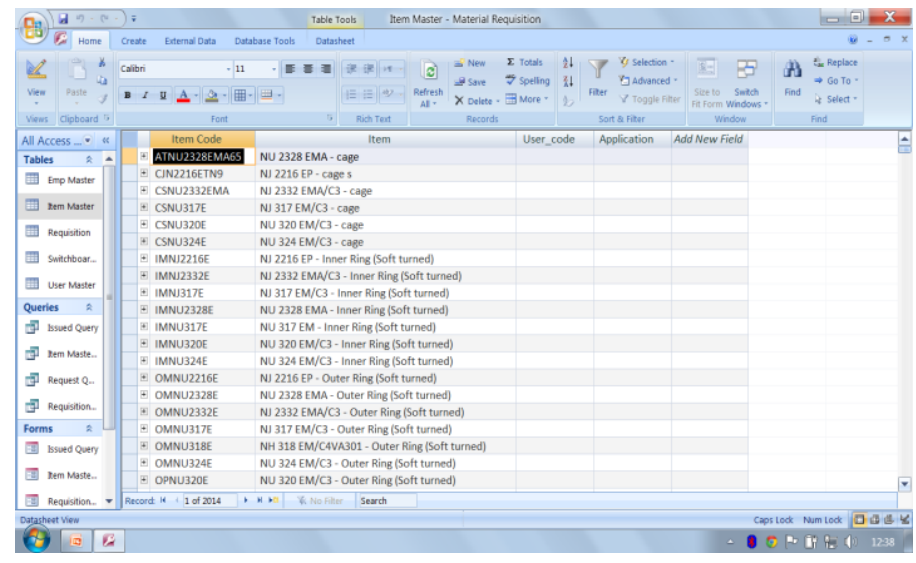

Fig. 8. TRB Rings Designation and Details

Another option can be accessed using this MIS, is to issue the requested material and this function needs to be accessed by warehouse department as shown in Fig.9. Here an order no. needs to be filled which is generated while accessing the material requisition option. By clicking this option a back end form opens as shown in Fig. 10 and this form needs to be filled so that database is created.

To refer the various requisitions that has made previously, there is another option called view requisition as shown in Fig.11. Once the view requisition option is checked it opens a dialogue box in which order number need to be entered. 


\section{Asia Pacific Journals}

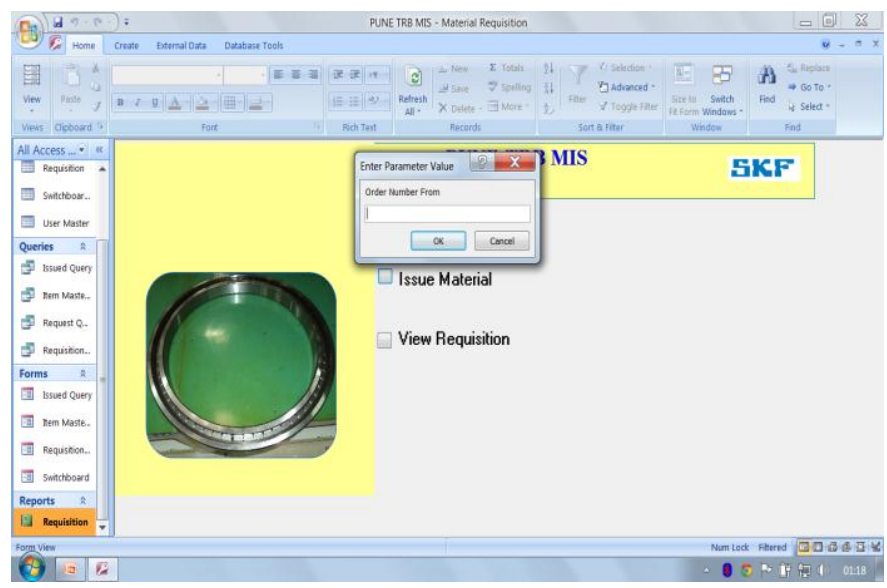

Fig. 9. Issue Material Option

While requesting for the material, a transaction ID has generated automatically this is also treated as an order number and this unique number need to be used for viewing

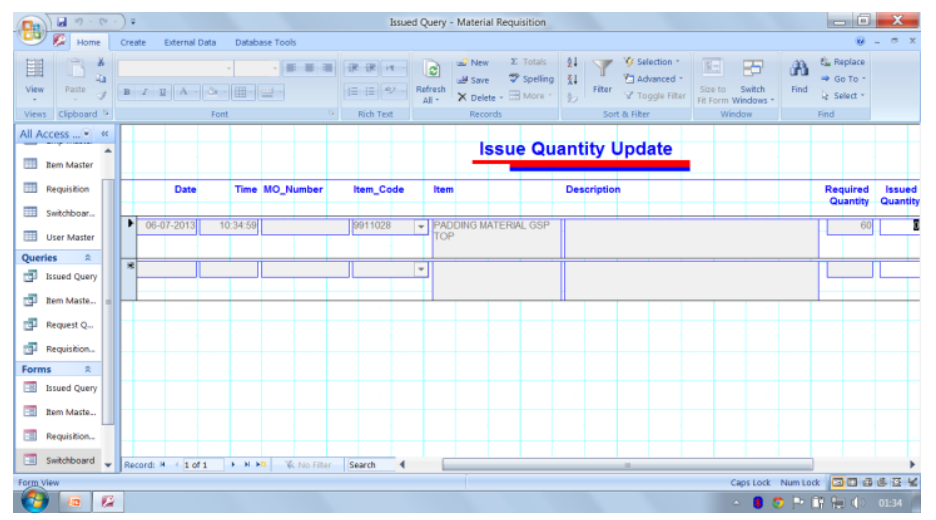

Fig. 10. Issue Quantity form

The various requisitions that has made previously, there is another option called view requisition as shown in Fig.11. Once the view requisition option is checked it opens a dialogue box in which order number need to be entered.

While requesting for the material, a transaction ID has generated automatically this is also treated as an order number and this unique number need to be used for viewing

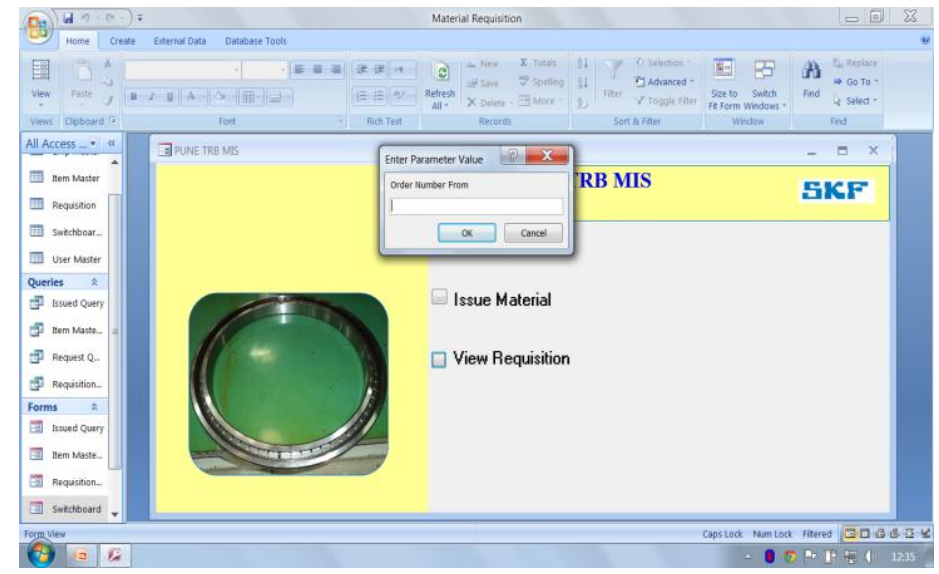

Fig. 11. View Requisition Option

any requisitions for future reference. All the previous raised requisitions with time and date of requisition along with the details of stakeholders is generated and saved automatically in the table as shown in Fig. 12.

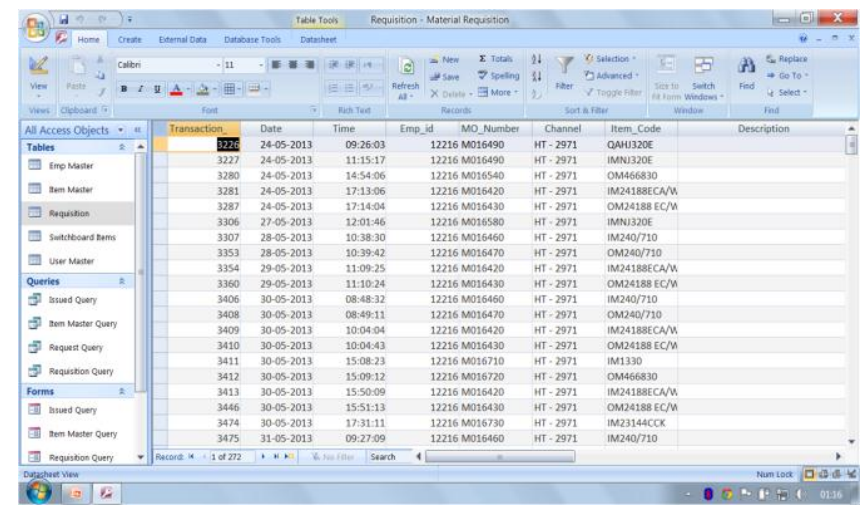

Fig. 12. Previous raised requisition details.

Once the order number is entered and after pressing $\mathrm{OK}$ button on the dialogue box appears while accessing view requisition option, a provision is there to generate a separate requisition slip which consist of all the necessary details of the particular material requisition. The requisition slip generated as shown in Fig.13, can be saved in any format like in word format and also its print out can be taken so that it act as a proof and also for further reference. 


\section{Asia Pacific Journals}

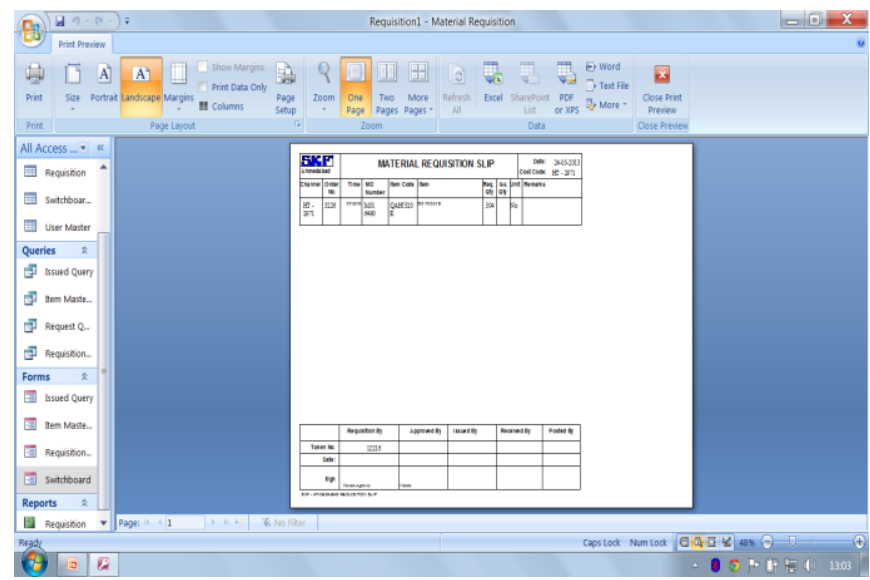

Fig. 13. Pune TRB Process Flow Chart

Since MS Access is open source software, there have to be a limited access option to this MIS and thus using visual basic code manager, provision is provided that only the concerned stakeholders have the access of this MIS. Total three departments are involved in this business area i.e. Supply chain department, heat treatment and SLS (SKF Logistic service) or say warehouse members. So, provision is provided for the concerned stake holders of the respective department to use this MIS for business purpose. Fig 14 shows the Login Form and this form displays first as any one start using the MIS.

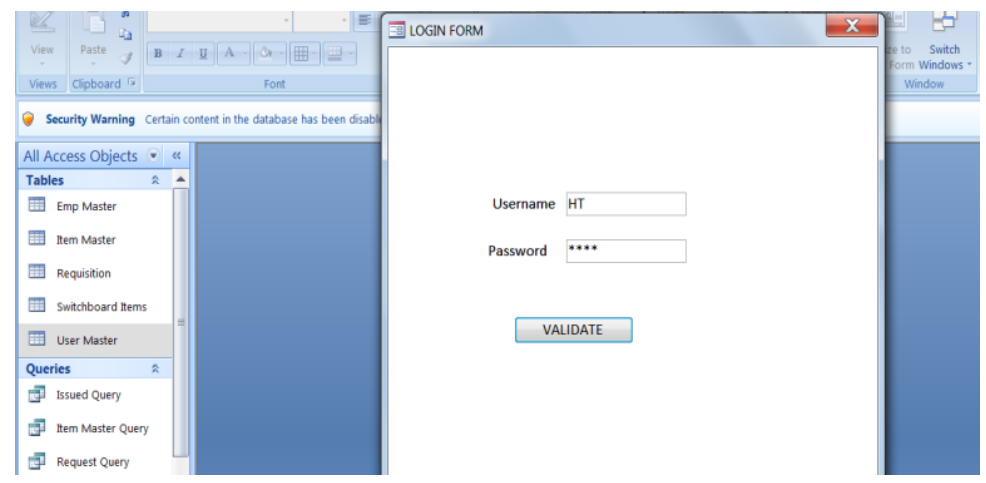

Fig. 14. Employee Login Form

\section{RECOMMENDATION}

To address the problem areas, recommendations are provided. Some of them have already implemented and remaining is on the drawing board.

\section{A. Status and Movement of material uncaptured.}

To address above problem, a separate MIS system is developed for Pune TRB rings so that material movement can be tracked.
B. Manual Handling of Rings.

A 5 Tonne crane as shown in Fig. 14 dedicated for the H.T. plant is installed to place the rings on girders so that little time loss occurs waiting for workers or stacker to get free.

At all docks, girders, and at bainite bath, sturdy mobile trolleys are used to place materials with heights adjustments as shown in Fig.15. It helps to hold a loaded pallet and/or parts. This will result in considerable time saving which generally lost in lifting items from/to the floor. These saves about 18-20 minutes per mesh loading.

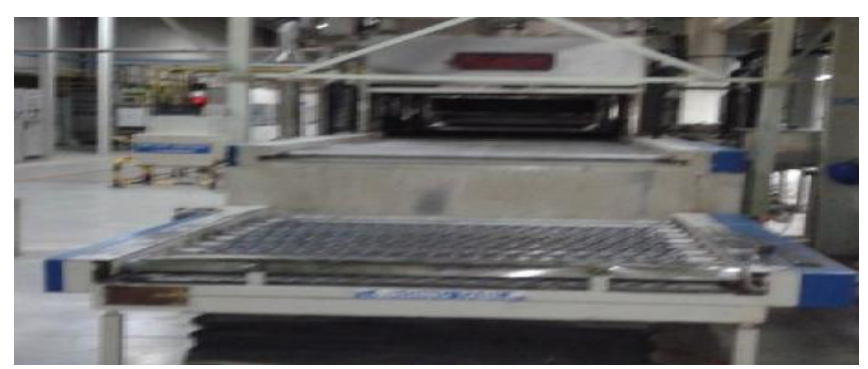

Fig. 15. Sturdy Mobile Trolleys

A particular area available near the H.T. Plant as shown in Fig is utilized as a storage area of raw TRB rings so that there will be ease in access for H.T. plant associates and also results in reduction in un necessary transportation time.

\section{Basic Facilities Deficit}

Fig.17 shows the wooden boxes which is available in ample amount which is started to use for dispatching rings to SKF Pune, instead of GSP'S so that there will be no problem regarding lack of transportation means.

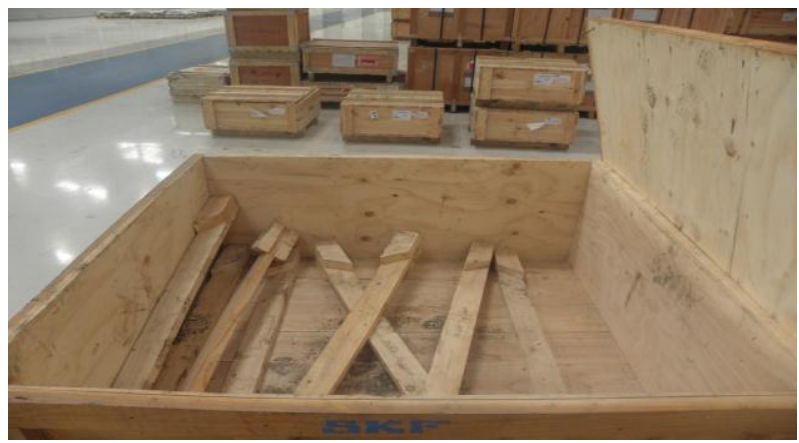

Fig. 16. Wooden Box Instead of GSP'S

\section{RESULTS OBTAINED}

Table IV shows the comparison of current state map and proposed future state map to highlight the improvements in process flow and improves lead time. 


\section{Asia Pacific Journals}

TABLE IV Comparison between CSM and FSM.

\begin{tabular}{|c|c|c|}
\hline Aspects & Current State Map & Future State Map \\
\hline $\begin{array}{c}\text { Rings Produced / } \\
\text { shift }\end{array}$ & 1172 Rings & 1286 Rings \\
\hline Value Adding Time & 200 Minutes & 175 Minutes \\
\hline Takt Time & 0.82 Minutes/Ring & 0.74 Minutes/Ring \\
\hline Approx. Lead Time & 23 Days & 12 Days \\
\hline Material issue Time & 40 Minutes & 15 Minutes \\
\hline
\end{tabular}

\section{CONCLUSION}

Following are the major conclusions on the basis of above study.

A. From time study analysis it is found that the total lead time to process the order is varying from 7 to 84 Days. However, As per SKF Pune, lead time should be around 12 to 14 Days.

B. By using the VSM principles it is found that as per the current conditions, the value added time for a batch production of TRB is 200 minutes. By applying the recommendations and following the future state of map, it results into 175 minutes of Value added Time.

C. As per the future state map, there is an increase in production capacity of rings per shift by 114 rings and takt time results from 0.82 to 0.74 minutes per ring.

D. A real time analysis of developed MIS is done to observe the time duration for this transactional activities and it is found that using MIS, whole activity get completed within 15 minutes while in earlier case it was around 40 minutes. So, it clearly shows the saving of at least 25 minutes per lot of Pune-TRB rings.

\section{References}

[1] W.M.Goriwondo, Samson Mhlanga , Alphonce Marecha" Use of VSM tool for waste reduction in manufacturing- A case study ", Proceedings of the 2011 International Conference on Industrial Engineering and Operations Management Kuala Lumpur, Malaysia, January 2011.

[2] Rahani AR, Muhammad al-Ashraf, "Production Flow Analysis through Value Stream Mapping: A Lean Manufacturing Process Case Study", IEEE Transactions on Magnetics, Procedia Engineering Volume 41 Page 1727 1734,2012
[3] Fawaz A. Abdulmalek, Jayant Rajgopal, " Analyzing the benefits of lean manufacturing and value stream mapping via simulation: A process sector case study", Int. J. Production Economics Engineering Volume 107 Page 223 - 236, 2007.

[4] Bob Barker, " Value-adding Performance Measurement: A Time-based Approach "Dorman Smith Switchgear Ltd, Preston, UK Page 33 - 40, 1992.

[5] Frank C. Garcia, "Using Value Stream Mapping as a Strategic Planning and Implementation Tool", Advent Design Corporation Bristol, PA, USA, 2003

[6] R.M. Belokar, Vikas Kumar, Sandeep Singh Kharb, " An Application of Value Stream Mapping In Automotive Industry: A Case Study", International Journal of Innovative Technology and Exploring Engineering (IJITEE) Volume-1, Issue- 2, Volume 1 July 2012.

[7] Y.K.Leung, K.L.Choy, "A real-time hybrid information-sharing and decision support system for the mould industry", Journal of High Technology Management Research Volume 21 Page 64-67, 2010.

[8] A Laufer, K.A Tenah "Introducing management information systems in medium sized Construction companies " Department of civil engineering, Haifa, Israel Volume 3 , 1985.

[9] Elizabeth A Williamson, Mike Jordan "Information system development within supply chain management" International Journal Of Information Management, Volume 24 Page 375-385, 2004. 